\title{
Body Control in American Cyberspace: A Study on Don Delillo's White Noise
}

\author{
Ruzbeh Babaee $^{1}$, Wan Roselezam Bt Wan Yahya ${ }^{1} \&$ Ida Baizura Binti Bahar ${ }^{1}$ \\ ${ }^{1}$ Faculty of Modern Languages and Communication, University Putra Malaysia, Malaysia \\ Correspondence: Ruzbeh Babaee, Faculty of Modern Languages and Communication, University Putra Malaysia, \\ Malaysia. E-mail: rbabaei30@yahoo.ca
}

Received: December 7, 2013 Accepted: December 27, 2013 Online Published: January 26, 2014

doi:10.5539/ass.v10n4p288

URL: http://dx.doi.org/10.5539/ass.v10n4p288

\begin{abstract}
Don DeLillo's White Noise (1984) is a cyberpunk narrative commenting on dystopia of late capitalism by illustrating the instability of the apparently safe and perfect life of a small town in North America. The dystopian society in white Noise is not a hierarchal world or a world in another time and space, as it is common in most dystopian narratives. It is a world that we may experience in our daily life. This study attempts to demonstrate that DeLillo criticizes the condition of the late twentieth century in which human beings are entrapped and become disembodied in cyberspace. This study also reveals that human beings live in a state of suspension in cyberspace. Furthermore, it is of great significance for this study to show that cyberspace is a control system that manipulates human beings through their bodies in the contemporary world.
\end{abstract}

Keywords: dystopia, cyberspace, hyperreality, pattern, death

\section{Introduction}

Cyberspace calls into question the traditional understanding of human being, as the autonomous source of truth, identity, and rationality. Many theorists and critics have seen the human is no longer in the center of the world, but instead a position that is "produced in a whole range of discursive practices-economic, social and political-the meanings of which are a constant site of struggle over power" (Weedon 21). Thus, shifting from center to position, the body is no longer regarded as a pre-existing phenomenon; but as something constantly reconstructed. In this regard, Katherine Hayles argues human beings become "a set of informational processes. Because information had lost its body, this construction implied that embodiment is not essential to human being" (4). She argues in cyberspace human body is not "usually represented as being a body. Only because the body is not identified with the self is it possible to claim for the liberal subject its notorious universality, a claim that depends on erasing markers of bodily difference, including sex, race, and ethnicity" (5). Hayles points to Gillian Brown, who sees "body as an object of control and mastery rather than as an intrinsic of the self" (5). Stephen doCarmo also observes people become an "object strategy." In cyberspace doCarmo, in "Subjects, Objects, and the Postmodern Differend in Don DeLillo's White Noise," considers DeLillo's characters, in White Noise, are caught is cyberspace. He states that DeLillo's "characters are caught between two equally seductive urges, one toward autonomy and individuality, or 'subjectness,' as we can call it, and another toward absorption and dispersal of the self into larger systems-a diametrically opposed 'objectness" (3). For doCarmo the "objectness" in White Noise is a part of a procedure that makes people able to join together to shape a mass giving the individual a much-required respite from the burden of "subjectness." Participation in the sort of mass, which doCarmo sees, needs a sense of self instructed via a system of informational flow. To join a mass that is distributed in time and space is to observe the universe in a way structured in much the same way as cyberspace

But, I see, in White Noise, Jack Gladney, the protagonist of the novel, has lost his subjectness as well as his objectness and becomes disembodied in order to achieve immortality.

Through a close analysis of White Noise, I demonstrate that cyberspace attempts to control the human body through the idea of death. Cyberspace highlights the idea of death, while it creates the illusion that human beings can achieve immortality through new technologies. The idea of death is a way that persuades people to rely on technology in order to rescue their bodies. In White Noise, DeLillo attempts to examine the development of computer technologies in cyberspace that forms computer-human interactions as a pattern for all experience, and observes the phenomenal world as something generated from a hidden set of data. 
In this study, I also suggest that DeLillo shows the construction of the human body in a cyberspace in which human beings live in a state of suspension between reality and simulation. Jean Baudrillard, in Simulacra and Simulation, observes that we live in a hyperreal environment that is more real than the original. Baudrillard claims that there is no border between real and simulation, but we have to remember that the real no longer exists by enforcing a false barrier between the two. On the other side, Katherine Hayles observes that living in a condition of virtuality implies we participate in the cultural perception that information and materiality are conceptually distinct and that information is in some sense more essential, more important, and more fundamental than materiality. (18)

Hayles explains that "how information lost its body, that is, how it came to be conceptualized as an entity separate from the material forms in which it is thought to be embedded" (2). In virtual reality, information can be transferred from one "body" to another. It means information can be converted from an electrical signal in a telephone wire into the percussive waves of sound we hear from the telephone earpiece. As Hayles observes information is more important than the body. The transformation from biological body to computer body is not as important as the static essence of the information. American cyberspace attempts to deny the significance of informational bodies and instead tends to convince people to absorb the information and data as real.

However, Hayles attempts to argue that information is introduced in some physical forms. She observes that if we change information's body, we also change the information itself. For Hayles, invisible information is given intellectual priority over visible bodies. On the other hand, for Baudrillard the visible "body" is all that one can find in the world. As Jean Baudrillard, in Simulacra and Simulation, argues "simulations have come to replace the real so that "it is no longer really the real, because no imaginary envelops it anymore. It is a hyperreality" (2). Reality is replaced by simulations. For Baudrillard, all available to us are observable bodies with no information supporting them. Baudrillard observes hyperreality is one that sees only bodies, only surfaces, only the visible, and dispenses with essences. Thus, according to Baudrilalrd:

Disneyland exists in order to hide that it is the 'real' country, all of 'real' America that is Disneyland... Disneyland is presented as imaginary in order to make us believe that the rest is real, whereas all of Los Angeles and the America that surrounds it are no longer real, but belong to the hyperreality order and to the order of simulation. (Simulacra and Simulation 12)

Hayles and Baudrillard consider the same issue from two different perspectives. Hayles observes the split between information and bodies, and she wants to reunite information and its body. But, Baudrillard observes a split between the real and the simulation, and claims the simulation comes to replace the real.

In this analysis, I propose that in White Noise, DeLillo sees human body rolling between information and body or reality and simulation. DeLillo sees that the visible or simulated world is produced by the hidden informational world. He also observes the invisible informational world is affected by the visible world.

For DeLillo, unlike Hayles, information is not as important as physical body; instead, information is an ever-hidden reality that produces what can be experienced in the simulated world. In other words, body is a visible form of information, and the invisible information is influenced through actions of the physical world. Cyberspace needs human bodies for transferring invisible information. This view is quite distinguished from Hayles and Baudrillard's observations of the relationships between body/information, and real/simulation.

For Hayles, virtual reality is that we find information as more important and real than bodies. But DeLillo considers both visible and invisible worlds. He sees cyberspace attempts to control the physical body through information and data, and simulation. Thus, technology can systematize the body based on particular cultural requirements.

I suggest that, for DeLillo, the reality has not been replaced by simulation, but has lost its essence and significance; and instead simulation has become important since human being finds it safer and more available than the reality.

\section{Body Metamorphosis in White Noise}

Maurice Merleau-Ponty argues the body shows our "being-in-the-world." In Phenomenology of Perception, he explains "The body is the vehicle of being in the world, and having a body is, for a living creature, to be intervolved in a definite environment, to identify oneself with certain projects and be continually committed to them" (94). Thus, through the body we become conscious of the universe. The body cannot be separated from the world. But, in White Noise the body is detached from the world. In fact, the body becomes a pattern or "an image drawn in a medium as fluid and changeable as water" (Hayles 26). Susan Martins observes for DeLillo the individual "no longer exist as an individual at all (89); instead individuals are absorbed into an electronic matrix. 
In White Noise, DeLillo shows that signs, words, TV messages, waves and radiation pass through the characters' bodies entrapped in an electronic matrix in which it is difficult to distinguish between pattern and presence. This electronic matrix is manifested in a cyberpunk environment that, according to William Gibson, is the sound of the 1980s. In his short story "Burning Chrome," Gibson defines the matrix as an abstract representation of the relationships between data systems. For DeLillo, the matrix is "white noise" in which a world of simulacra is created. Simulacrum is a world of pattern that "[interacts] with electronic images rather than with a materially resistant text." In this simulated world "[we] absorb through [our] fingers as well as [our] mind a model of signification in which no simple one-to-one correspondence exists between signifier and Signified" (Hayles 26). Thus, the body becomes a "visual display" rather than a "material object" (ibid) in cyberspace in which "pattern and randomness [are] more real, more relevant, and more powerful than presence and absence" (ibid). In cyberspace we are forced "to learn how to look," how "to open [ourselves] to the data. TV offers incredible amounts of psychic data. It opens ancient memories of world birth, it welcomes us into the grid, the network of little buzzing dots that make up the picture pattern" (61).

DeLillo's White Noise illustrates that technology disembodies human beings from their physical bodies, and instead human beings embody data and information. For DeLillo, our bodies become only shells that carry data and information and we are no longer alive inside; we become pattern rather than presence. We become the living dead with new images about ourselves. As Jack Gladney, the protagonist of the novel, states: "Our images appeared on mirrored columns, in glassware and chrome, on TV monitors in security rooms" (100). Jack sees his body is disembodied through technology and becomes a pattern or an image of a previous physical body. For DeLillo, our body becomes a pattern in American cyber culture. As I will discuss in the following segments, in White Noise, human beings tend to become a pattern in order to escape death. Cyberspace creates the illusion that people can achieve immortality through absorbing technology.

\section{Cyberspace Death Control}

Jack Gladney believes that he has to adopt "the system," a mainframe that, he thinks, can bless or curse his life, based on the extent to which he directs himself in a suitable fashion. For Jack "the system" is blessing. It is a cyber-system that Jack thinks gives him power. DeLillo illustrates Jack's involvement in "the system" through working with the ATM:

I went to the automated teller machine to check my balance. I inserted my card, entered my secret code, tapped out my request... The system had blessed my life... The system hardware, the mainframe sitting in a locked room in some distant city. What a pleasing interaction... system was invisible, which made it all the more impressive, all the more disquieting to deal with. But we were in accord, at least for now. The networks, the circuits, the streams, the harmonies. (55)

Through Jack's interaction with a machine, the data pass through both the machine and his body. For paying his bill, Jack follows 12 steps: step 3 is "sign your check"; step 10 is "secure the envelop flap"; step 11 is "place a stamp on the envelope, as the post office will not deliver without postage (265). Jack attempts to conform to the procedure of the system, by means of that becoming part of the system. Thus, he is redefined as a code, a number, a pattern: "REMEMBER. You cannot access your account unless your code is entered properly. Know your code. Reveal your code to no one. Only your code allows you to enter the system" (339). Mojca Krevel explains that Jack "gains new characteristics according to the networks of information forming more or less bizarre situations around him" (123-124). The code makes the subject a number, an abstraction. It is the confidential information shared by the subject and the invisible administrator of the system of electronic funds.

In cyberspace, people think that they are inside the ATM, the TV, and the computer since this thought gives them a sense of immortality. In fact, it is hyperreality that creates such a sense of immortality in individuals. White Noise represents a perfect picture of this system, this usurpation of death. DeLillo depicts SIMUVAC, for "simulated evacuation," in a real environmental accident, the release of a deadly airborne toxin called Nyodene $\mathrm{D}$, as a kind of simulacra. A SIMUVAC technician says to Jack, we don't have our victims laid out where we'd want them if this was an actual simulation. In other words we're forced to take our victims as we find them. We didn't get a jump on computer traffic. Suddenly it just spilled out, three-dimensionally, all over the landscape. You have to make allowances for the fact that everything we see tonight is real. There's a lot of polishing we still have to do. But that's what this exercise is all about. (162)

The technician is immersed in the simulation (Wilcox 351) that becomes "a feature of everyday life" (Hayles 25). In other words, according to the SIMUVAC technician, exercising simulation becomes a habit of our daily life. The SIMUVAC technician would "polish" the real for improving the simulacra-a simulation produced through the computer, by the flow of data and programs. The technician represents himself as a subject of technology, as 
Jack wants to have "this man" since the SIMUVAC can have "access to data". Jack states, "I was prepared to be servile and fawning if it would keep him from dropping casually shattering remarks about my degree of exposure and chances for survival" (162). Jack participates in his own simulation because he does not like to face with the reality. Nick levey states, "when Jack faces with the reality, data and information lose their validity and significance" (12). Since there is the concern that he might have been exposed to the toxic cloud, he speaks with one of the SIMUVAC technicians, whose computer terminal connects to Jack's "data profile," subsequently called his "history" (163). It encodes Jack's past, and, since he eagerly responds to it as a dominant force, it embraces his identity. Jack becomes voluntarily submissive to this representative of technology, who holds the key to Jack's electronically meditated destiny, the "computerized dots that registered [his] life and death" (163).

The idea that the computer is able to calculate an individual's destiny is believed by people who reduce life to data, who see life as a system. After launching a "massive data-base tally" on behalf of Jack, the SIMUVAC decodes the meaning of the results, the "bracketed numbers with pulsing stars" (163) filling the screen: the SIMUVAC says to Jack, "It just means you are the sun total of your data. No man escapes that" (165). Jack sees that it "is now official, according to the computer. I've got death inside me" (175). For jack the computer becomes a judge, a "verdict" (199); he sees his death is "in the works" (88). This last statement can be true, but not in the way he sees. While death is "inside" him, as it is inside all human beings, the "works" points to the computer that predicts his destiny.

Although this death is a computerized death, Jack has faith in it. His statement "matter-of-fact, tonelessly, in short, declarative sentences" (232) suggests a discourse more "digital"- more in line with what Anthony Wilden sees as "the dominant logic of our society, the left-brain logic of analytic and digital communication" than the variety of human speech (61). Jack is immersed in the doctrine of the SIMUVAC that "We are the sum total of our data" (232).

Jack's death is not "personal" since he becomes a pattern. According to Wilcox, it is "death by printout" (353). When Jack goes for a check-up, he sees that there are "no startling umbers on the printout. This death was still too deep to be glimpsed" (234), as if he sees death in the numbers. Jack wants to reduce himself to data in order to escape mortality.

Later, Jack gets into "a brand-new facility called Autumn Harvest Farms" including advanced computers for analyzing the data (300). Here, Jack is encouraged to tell the story of his life through a computer, typing "the story of my life and death" (316). He says more of himself, thus when a technician "transmits a message that would make Gladney's body transparent" - his "screen" body, not his real body- Jack finds himself in the digital domain: "I heard magnetic winds, saw flashes of northern light. People crossed the hall like wandering souls, holding their urine aloft in pale beakers" (317). He assumes a computerized domain "where charged particles collide, high winds blow" (374), pass through the "imaging block," which fills Jack with fear. Giving up the secrets of his body, Jack sees the paranoid fear of people who enter the system: "I am afraid of the imaging block. Afraid of its magnetic fields, its computerized nuclear pulse. Afraid of what is knows about me" (374).

Jack's confrontation with a technological death, Nyodene D, and his confrontations with the SIMUVAC and Autumn Harvest Farms have strengthened his mortality. He has a computerized fear, a computerized death. He knows that the system controls human life. He knows that he becomes a pattern. When he says that the "holographic scanners, which decode the binary secret of every item, infallibly" and "this is the language of waves and radiation, or how the dead speak to the living" (375), he refers to a mystery in our life. The doctor knows the symbols; the computer knows your code, your "binary secrets." "We are the sum total of our data" and we participate in feeding the simulation, and in representing ourselves as simulated figures. Indeed, DeLillo discloses the extent to which computer technology controls, guides, and manipulates us. For DeLillo, in a digital environment, people become cyber body that is " "released from its physical restrictions, a body evacuated, devastated, disintegrated, disappearing"" (Cavallaro 75). In cyber culture, which "coexists with an increasing infiltration of the body by technologies that seem to take its materiality away" (Cavallaro 75), people conform to their digital shadows in the database, allowing their body to be directed by digital information. In fact, in cyberspace, people exchange their bodies with data and information. Thus, the body becomes a source of control in cyberspace.

\section{Dancing on Suspension Bridge}

White Noise illustrates the American home as a source of death and the fear of death. DeLillo shows that the simulation of these events through the television produces a significant distance between simulation and reality. For instance, when Jack and his family gather to watch TV, they are immersed in disasters presented on Television: "There were floods, earthquakes, mud slides, erupting volcanoes... Every disaster made us wish for 
more, for something bigger, grander, more sweeping" (75-76). Jack and his family find themselves to live in the simulation. DeLillo shows that the media presentation of death creates a simulation of the "real" life events. But when the toxic air event happens, people face with the reality. The toxic event is not a simulation. Thus, people can call into question the nature of the simulated world, and ask how is it possible to face the reality in the simulation? In the reality, the simulations are no longer valid. Thus, people look for way to escape that reality. Jack attempts to convince himself that the toxic event is not harmful for him, as a college professor:

People in low-lying areas get the floods, people in shanties get the hurricanes and tornados. I'm a college professor. Did you ever see a college professor rowing a boat down his own street in one of those TV floods? (133)

Jack looking for a way to escape the reality of the toxic event finally accepts that "air-raid sirens" are so close to them and they are "negatively affected" (137). In this scene, Jack wants to postpone the reality but he cannot, because he can see, hear, and feel that "cloud of deadly chemicals" is spreading in the air (139). DeLillo demonstrates that reality cannot be postponed or replaced by simulation when we face with it.

After the toxic event, the SIMUVAC attempts to simulate disasters for making people prepared for the real event: "The more we rehearse disaster, the safer we'll be from the real thing" (236). In fact, it is a rehearsal to train people how to postpone the reality. For DeLillo, The SIMUVAC no longer deals with death and disaster like the one experienced during the toxic event; instead, the simulation serves its own goal: the volunteers simulate for making the "real" toxic event disappear. For DeLillo, once the "real" disappears, the simulation itself becomes the objective.

Although death is simulated in cyber culture, once the fear of death becomes real, then the idea of death becomes real. DeLillo shows people can watch disasters on TV or they can turn off the programs whenever they want; however, when Jack is infected by the toxic event, death becomes too real for him, as he is unable to escape the fear of death. Thus, he must "kill to live" (335). Jack's fear of death detaches him from his self. But by shooting Mink, he becomes reattached to his self-consciousness: "I looked at him. Alive....I felt I was seeing him for the first time as a person" (360). Here, Jack is no longer detached from his self: he finds Mink as a human and even attempts to rescue him.

Before murdering Mink, Jack had a different understanding about death and killing, but when Mink's blood covers Jack's hands, he stagers back and watches blood dripping from his fingers (360). In this scene, he faces with the reality of death and killing. As Jack goes back to take in "the scene of squalid violence and lonely death at the shadowy fringes of society," Mink takes the gun, shoots Jack, and almost brings Jack to the reality (360). "The blood that pours from Jack's wound matches Mink's, and he conceives of Mink as more alike than different from himself" (Clark 42-43), "seeing him for the first time as a person" (360). Here, Jack can touch the idea of death and life. Jack sees the death in front of his eyes. Thus, DeLillo demonstrates that in the presence of death, the real becomes inevitable and inescapable. Killing Mink is not an act of simulation: it is a real scene of murder. In this scene, Jack feels more human, since he is not in simulation and is in reality. He finds a feeling of sympathy. It shows that Jack understands the reality of death as a phenomenon quite different from its media presentation or its simulated one. Jack feels bothered by murdering. When he comes back home, he says: "[I] feel the pain in my wrist, the heightened pulse" (369). His words show how the act of murder affects his body. The act of murder not only does not help Jack overcome his fear of death, but also makes him closer to the reality of death. However, living in cyberspace makes Jack able to forget the reality and reconnect himself with the simulation. In fact, he wants to reconnect himself with the simulacra in order to escape the reality of that murdering scene, as he states, "There is nothing to do but wait for the next sunset, when the sky would ring like bronze" (369). DeLillo demonstrates that people are in a state of being suspended in cyberspace; they want to know the reality, while at the same time they escape it to the simulation.

\section{Body's Obedience to Simulation}

Throughout the novel, in a number of scenes, Jack represents himself as a submissive body in cyberspace. When Murray Jay Siskind, a colleague of Jack Gladney's, was talking of the cultural significance of the barn they visited, Jack just listened without expressing his own idea, as if he were Murray's student. Throughout the novel, Jack shows such a submissive approach by accepting the views of others around him. Murray often represents explanations that make Jack able to incorporate his experience into a simulated world. Although Murray's views are sometimes strange; they let Jack see the world in familiar manners. In fact, Murray keeps a worldview in which everything falls into an obvious frame. For Murray everything is clear, and even if Jack does not completely believe him, he still finds Murray as maintaining a view from which the world can be perceived. Even though Murray tends to "immerse in American magic and dread," he sees himself as a person with more 
answers than questions: "The students are bright and responsive. They ask questions and I answer them." He sees himself at the center of the world: "They jot down notes as I speak. It's quite a surprise in my life" (22). Indeed, Murray wants to "immerse" himself to reflect the significance of simulation. Murray suffers from megalomania- the idea that I will explore in DeLillo's Cosmopilis.

Murray also acts like an agent of cyberspace. Through the idea of death he attempts to convince Jack to put his faith in technology:

You could put your faith in technology. It got you here, it can get you out. This is the whole point of technology. It creates an appetite for immortality... Technology is lust removed from nature. (328)

Murray represents a god-like figure of technology. He continues, it's what we invented to conceal the terrible secret of our decaying bodies. But it's also life, isn't it? It prolongs life, it provides new organs for those that wear out. New devices, new techniques every day. Lasers, masers, ultrasound. Give yourself up to it, Jack. Believe in it. They'll insert you in a gleaming tube, irradiate your body with the basic stuff of the universe. Light, energy, dreams. God's own goodness. (ibid)

He believes that technology is invented as a solution to our physical death. Finally, Jack accepts Murray's words and says, "I don't think I want to see any doctors for a while, Murray, thanks" (ibid)

Murray even provides Jack with another solution for death. He tells Jack, "there are two kinds of people in the world. Killers and diers" (333). Then, he asks Jack to be a killer if he wants to avoid his own death. His suggestion seems to give Jack a feeling of relief and help him to overcome his fear of death. Murray states: "The more people you kill, the more power you gain over your own death" (335). His theory is attached to "massacres, wars, and executions." He sees his theory as "a form of rebirth. The dier passively succumbs. The killer lives on." (334)

Murray tells Jack that he finds a secret ability to kill in him, "a sludgy region you'd rather not know about" (336). Jack at first prevaricates and states "I suppose so. It can be. It depends" (336). But when Murray insists, Jack says “It's there, Murray. So what?" (336). Then, he discloses the reason he attempted to extract this answer from Jack. "I only want to hear you say it. That's all. I only want to elicit truths you already possess, truths you've always known at some basic level" (336). Murray helps Jack imagine himself within a simulated context. In fact, he attempts to show that everything is normal and familiar to human being in cyberspace.

\section{Conclusion}

In White Noise, DeLillo depicts a dystopian society in which the body is transformed into a pattern of itself in order to escape death: it is the illusion that cyberspace has created for human beings in order to manipulate their bodies. We are immersed in a cyberpunk environment that enslaves our body and does not let us make any change.DeLillo demonstrates that in cyberspace, reality is not replaced by simulation, but has lost its essence and significance; and instead simulation has become important since human beings find it safer and more available than the reality.

\section{References}

Britt, T. (2006). White Noise and the American Novel. In T. Engles, \& J. N. Duvall (Eds.), Approaches to Teaching DeLillo's White Noise. New York, NY: Modern Language Association of America.

Cavallaro, D. (2000). Cyberpunk and cyber culture: Science fiction and the work of William Gibson. The Athlone Press.

Clark, R. (2012). Colored Spots: Race Constructions at the Periphery of Don DeLillo's White Noise. The Sigma Tau Delta, 36.

DeLillo, D. (2011). White Noise. Pan Macmillan.

doCarmo, S. N. (2000). Subjects, Objects, and the Postmodern Differend in Don DeLillo's White Noise. LIT, 11, $1-33$.

Hayles, N. K. (1999). How we became post human: Virtual bodies in cybernetics, literature, and informatics. University of Chicago Press. http://dx.doi.org/10.7208/chicago/9780226321394.001.0001

Krevel, M. (2004). Concept of Self in Avant-Pop Literature. Slovene Association for the Study of English, 1(1/2), $115-124$.

Levey, N. (2013). Crisis and Control in Don DeLillo's WHITE NOISE. The Explicator, 71(1), 11-13. http://dx.doi.org/10.1080/00144940.2012.758613 
Martins, S. S. (2005). White Noise and Everyday Technologies. American Studies, 46(1), 87-113.

Merleau-Ponty, M. (2002). Phenomenology of perception. Phenomenology of Perception. Trans. Colin Smith. London: Routledge (Original work published 1945).

Weedon, C. (1987). Feminist Practice and Poststructuralist Theory. London: Blackwell.

Wilcox, L. (1991). Baudrillard, DeLillo's "White Noise", and the End of Heroic Narrative. Contemporary Literature, 32(3), 346-365. http://dx.doi.org/10.2307/1208561

Wilden, A., \& Hammer, R. (1987). The rules are no game: The strategy of communication. London: Routledge \& Kegan Paul.

Williams, J. J. (2012). The Rise of the Academic Novel. American Literary History, 24(3), 561-589. http://dx.doi.org/10.1093/alh/ajs038

\section{Copyrights}

Copyright for this article is retained by the author(s), with first publication rights granted to the journal.

This is an open-access article distributed under the terms and conditions of the Creative Commons Attribution license (http://creativecommons.org/licenses/by/3.0/). 